Brit. F. industr. Med., 1968, $25, \mathrm{I}$.

\title{
British Journal of Industrial Medicine
}

\author{
The First 25 Years
}

\begin{abstract}
'The new journal (wrote the Lancet in 1944), edited by Dr. Donald Hunter, closely resembles the Archives of Disease in Childhood in format (with a touch of lead in its cover) and is also published under the auspices of the British Medical Association. It is intended for both whole- and part-timer-for the mass of doctors who cannot do their best for their patients unless they study the conditions in which people work, in factory, mine, shipyard, bus, office or shop. Many of these doctors are cut off from lectures and libraries-more especially in war-time-and have little time for selecting their reading from a multitude of journals. If the new quarterly helps them to bring and keep their knowledge of industrial problems up to date the trouble of launching it in war-time will be well repaid.'
\end{abstract}

It was at the end of 1942 that the Association of Industrial Medical Officers raised the question of publishing a journal dealing with industrial medicine. The vital importance of the health of the industrial worker to Britain at that stage of the war made the idea readily acceptable in spite of the great difficulties of publishing a journal at such a time. Owing to the ill health of the Editor of the British Medical fournal (N. G. Horner) the Deputy Editor (H. A. Clegg) represented the B.M.F. in the many discussions that took place before and after the proposal was accepted. Arguments about the policy of the journal really centred around the position and interests of the Association of Industrial Medical Officers. There was a feeling among those who represented the Association that the new journal was in effect to be its official organ. H. A. Clegg contested that view and urged that the British fournal of Industrial Medicine should be a quarterly clinical and scientific periodical, which would put on record the results of research work conducted in this field of medicine. This was in line with the publishing policy of the Journal Committee of the British Medical Association, and the new journal, it was argued, should follow in this respect the standards adopted by the three previous quarterly journals published by the B.M.A., namely, the Fournal of Neurology and Psychiatry, the Archives of Disease in Childhood, and the British Heart fournal, which was first published before the outbreak of the war.

The first meeting of the Editorial Board was held in December 1942 under the chairmanship of G. S. Parkinson. The following were present: A. J. Amor, H. Bashford, W. Blood, J. C. Bridge,
M. W. Goldblatt, R. E. Lane, E. R. A. Merewether, D. C. Norris, R. S. F. Schilling, and D. Stewart. Several members of the board, although already distinguished in the field of industrial medicine, were still young enough to lead the new journal through most of the next 25 years.

Many people, not the least of whom was Dr. (later Sir Henry) Bashford, shared the burden of getting the journal launched. The difficulties arising from war-time shortages of paper and the lack of time available to leaders of industrial medicine to submit scientific papers were overcome by the drive and enthusiasm of Donald Hunter, the first editor, supported by his colleagues, Donald Norris and Kenneth Perry, and by Donald Stewart. Like all periodicals, the B.F.I.M. had its ups and downs, and one of its most awkward moments came in 1950 when, in the prolonged absence of Donald Hunter in Australia, it was found that the cupboard had become almost bare, and the Editor of the B.M.F. had perforce to join with Kenneth Perry in a minor rescue operation to keep the journal afloat. In 195 I Richard Schilling took over the editorship and, with the advantage of the experience of his predecessors, he took the journal up to the high scientific standard which it has maintained. As the size of the journal and the work associated with it grew, he appointed two assistant editors. This system has continued and the assistant editors play an essential role in the running of the journal. For the past Io years there has been one from the M.R.C. Pneumoconiosis Research Unit and one from the M.R.C. Toxicology Research Unit.

The important decision to publish papers of only the highest scientific quality determined the 


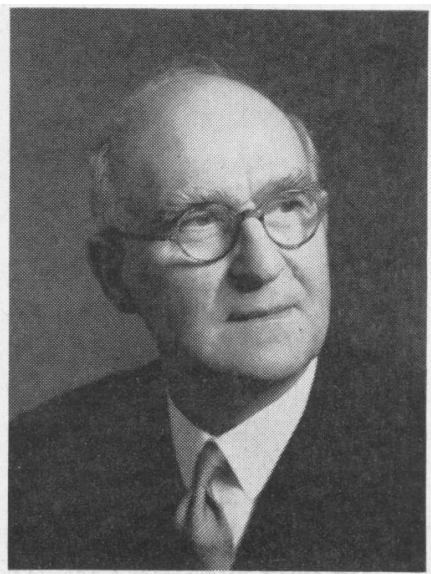

D. Hunter, editor $1944-50$

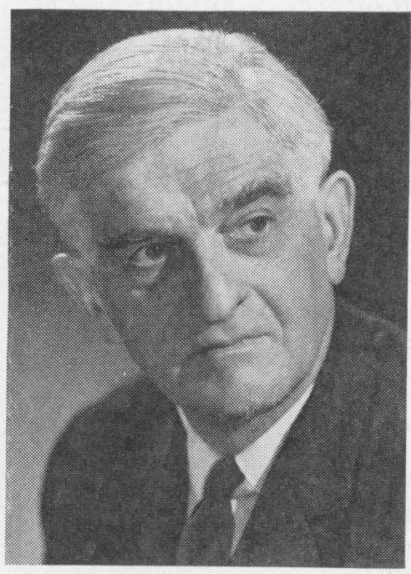

R. S. F. Schilling, editor 1951-56

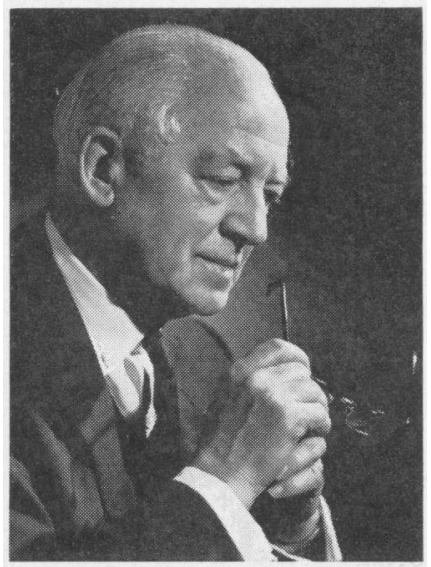

R. E. Lane, editor $1963-65$

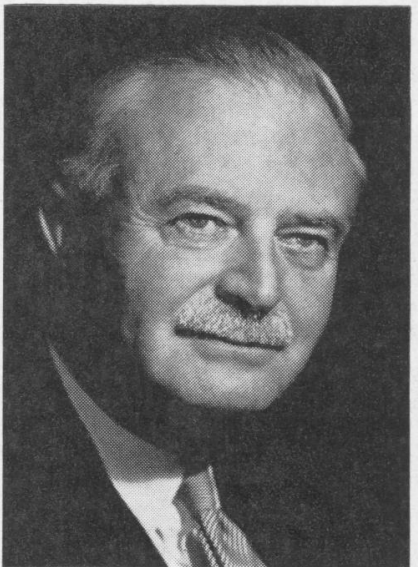

L. G. Norman, editor 1957-62

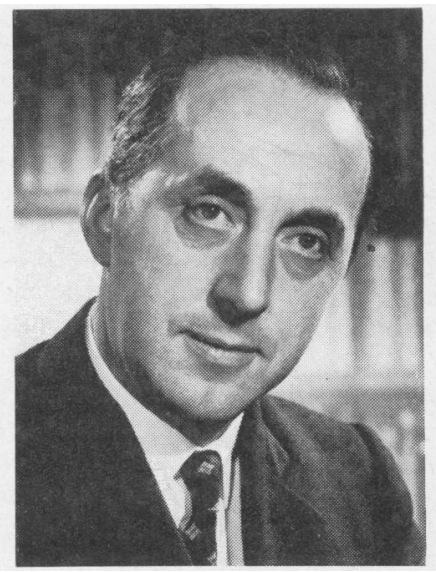

W. R. Lee, editor 1966'- 
nature of the journal. This emphasis meant that the journal might fail to help the 'mass of doctors' to 'keep their knowledge of industrial problems up to date'. The decision, so right in retrospect, was made easier by the independent publication from 195I of the Transactions of the Association of Industrial Medical Officers, which catered for the day-to-day interests of both part-time and fulltime industrial medical officers. Another favouring circumstance was the development about this time of the university departments of industrial medicine. Not only were they beginning to raise the standard by their contributions, but also their influence on the papers contributed by practising industrial medical officers was becoming apparent. From the start, the journal has been supplied with papers of the highest quality from a number of Medical Research Council units. Many of their members, like members of university departments, have served on the Editorial Committee and, by constructive review of papers submitted, have helped authors to revise their work or present their papers more clearly and cogently.

In 1956, when Schilling handed the editorship to Leslie Norman, the journal was clearly established as a scientific journal of high repute, second to none in the field of industrial medicine. Norman improved the presentation of papers by prefacing them with an abstract. His other major contribution was to organize efficient communication between the referees.

As with all the special periodicals published by the B.M.A., the Editor of the B.M.F. is ex officio a member of the Editorial Committee and from the beginning has been responsible to the Journal Committee for the format and typography of the B.f.I.M. and for providing the professional services of a sub-editor. This has meant that the editors of the B.F.I.M. have been able to concentrate on the policy of the journal and the selection of papers and have been freed from all the technical aspects of editing. On the business side, too, the B.M.A. has always undertaken to meet the financial losses of the B.F.I.M. and, of course, receives surpluses when they occur. The Manager of the B.M.F. is responsible for all business matters, such as the choice of printers, collection of advertisements, and promotion of circulation. It might be added that the editors of the B.F.I.M. have had full authority to reject advertisements thought to be unsuitable for their periodical. Thus the success of the journal has been due in no small way to the services provided by the editorial and business departments of the British Medical fournal.

Successive editors have maintained the policy of publishing papers of only high scientific value. From time to time this has disappointed some readers who still see the role of the journal as it was originally conceived-to help industrial medical officers to keep their knowledge up to date. Rather the journal has become an information channel for fundamental studies on all aspects of industrial medicine, whether contributed from formal research centres or, as frequently happens, from the careful observations of industrial medical officers in the field. Clearly the progress of industrial medicine needs information from both these sources. The Miscellanea section was started in I953 by Schilling to include 'scientific observations which are still in the preliminary stage, and notes of special interest. . . . Where the theme of a book inspires the reviewer to expand the usual book review and add to it from his own experience here is the place for such an essay. . . .

Because of the policies adopted and worked out over the past 25 years the British fournal of Industrial Medicine has achieved an international reputation. It might seem that there is now little call for change. The usefulness of the journal, however, will be maintained and increased only if it continues to uphold high standards and is prepared to adapt itself to new conditions and developments as they arise. In seeking to realize these objectives the journal will be fulfilling the ideals of its sponsors. 